\title{
The Economic Impact of Immigration
}

This submission is in response to a request from the Clerk to the Economic Affairs Committee for further information on migration to the North of England, with particular reference to skills. It is an individual rather than School or University response. The following comments are concerned with Polish migration and are based on nearly three years accrued knowledge of Polish migrant workers following a series of projects in the North of England that either I have undertaken myself ${ }^{1}$ or in one case been part of a research team ${ }^{2}$. Although, this work has not sort to specifically investigate the introduction of skilled Polish workers into the North of England I consider that it provides a context into which many skilled Polish workers have been introduced.

\section{Background}

1.1 Before discussing Polish migration to the North it is worth again highlighting the importance of differentiation when discussing migrant groups. Not only within groups themselves, for example around social class, gender and age, but also between those like the Poles who are entitled to live and work in the UK with little restriction. In contrast to other migrant groups who are often recruited via work permits or are sometimes importantly undocumented within the labour market. It is also important to record that for a number of reasons, most notably the easily accessible transport links, the early signs are that the Poles are more transitory than many other prior groups of migrant workers (Fitzgerald, 2008). Finally, the point must be made that as with other early migrations to the UK Polish migration to the North is still developing, as communities establish themselves and newly arrived workers decide on what basis to remain and how secure they feel in their new surroundings.

\footnotetext{
${ }^{1}$ Fitzgerald, I. (2008) A moving target: The informational needs of Polish migrant workers in Yorkshire and the Humber, Leeds: Yorkshire and the Humber TUC; Fitzgerald, I. (2007a) An Analysis of the North East Worker Registration Scheme Data, briefing paper for the Talent North East steering group, 3rd May 2007; Fitzgerald, I. (2007b) Working in the UK: Polish migrant worker routes into employment in the North East and North West construction and food processing sectors, London: TUC; Fitzgerald, I. (2006) Organising Migrant Workers in Construction: Experience from the North East of England, Newcastle upon Tyne: Northern TUC; Fitzgerald, I. (2005) Migrant Workers in the North East of England, Newcastle upon Tyne: Northern TUC.

${ }^{2}$ Banks of the Wear (2007) Enterprise for BME Communities, Refugees and Migrants, One NorthEast.
} 
1.2 Salt and Millar (2006) ${ }^{3}$ describe the entry of the EU accession eight (A8) workers, following May 2004, as the largest ever in-migration to the UK, with the Poles the largest ever single ethnic group. This migration took all by surprise and left many at a local level having to 'fire-fight' the numerous issues that have arisen. Migration has been dramatic for many small towns and villages in the North, with the accession monitoring reports stating that the North has a larger number of registered A8 workers than are registered in London and the South East. Although, following a request through freedom of information ${ }^{4}$ it is clear that the North East has the lowest number of registered A8s in England (Fitzgerald, 2007a).

1.3 With an increasing number of Polish workers in the North issues become not only where people are living, for local service provision, but also where they are employed. A growing amount of research; the accession monitoring reports; and my northern studies highlight that this is often in low paid sectors such as food processing. It is also clear, though, that Polish workers are ubiquitous and are evident in other more skilled sectors and occupations, including even exploring the possibility of starting new UK businesses (see Banks of the Wear, 2007). Importantly, for some of those in lower skilled occupations, this may not be due to choice but more directly due to either a lack of information on higher skilled work (Fitzgerald, 2008) or more importantly a lack of language skills. In particular the Committee will also be aware that though there has been progression with the mapping of Polish and UK qualifications, this can still remain a barrier with job-to-job mobility. To begin to unpick this further the following section discusses the recruitment of Polish migrant workers in construction and food processing. It is clear, though, through discussions with key respondents at an international, national and regional level that these sector findings have some value when applied to the wider labour market.

\section{Recruitment of Polish workers in the North}

2.1 Although, still not fully granted, one of the four main freedoms of the European Treaty is the right of mobility for European workers. As part of this the EU in 1993 created EURES to facilitate this movement and allow easier job-to-job mobility. This should have helped facilitate skill needs at a regional and local level with assistance given to both employers and European migrants. However, the reality found in the North of England was that two of the three EURES advisers present, noted limited or no engagement with the increasing number of Polish workers found in food

3 Salt, J. and Millar, J. (2006) 'Foreign Labour in the United Kingdom: Current patterns and trends', Labour Market Trends, ONS, October 2006.

4 The accession monitoring reports confusingly combine the two RDA regions North East and Yorkshire and the Humber into one 'North East' block. 
processing. Further, one of these advisers admitted that his recruitment engagement with the overall numbers of A8 workers coming into his region had been limited (Fitzgerald, 2007b). At a recent Polish government launch of a report into the treatment of A8 migrant workers 5 , an EU official spoke of the need to reinforce the role of EURES' ${ }^{6}$. In the North it seems that often freedom of movement has been exactly that, with limited co-ordination by government or other agencies in this process. So if EURES are not the main facilitators of mobility how have Polish workers found their jobs and how have companies managed their recruitment needs?

2.2 Fitzgerald (2007b) sort to explain this with regard to construction and food processing in the North East and North West. Whilst the mapping of job-to-job mobility was not the aim of the project, its findings with regard to recruitment have relevance to other sectors in which Poles are working. The project uncovered three main recruitment routes into employment: on-spec recruitment, direct company recruitment; and direct agency recruitment. With no identifiable differences between the introduction of skilled and unskilled labour.

2.3 On spec recruitment relates to Polish workers who have made the decision to migrate to the UK to work without a particular job being offered. This type of movement was identified as being prevalent in the early days of Polish accession migration. With Poles having a vague idea of where to go and what job to take, money was normally available for a short period to cope without a job. This was now reported as becoming more structured with the use of family and friend networks to identify both geographic and potential employment locations. Agencies and direct employers were also beginning to use currently employed family and friends to identify Polish based recruits when needed. The study indicates that in many cases if people use this route now without a definite job offer they are more likely to arrive in the UK with an idea of where to go and what to do (for example primed with information from either websites or through family and friends). Although information from these sources may be limited or simply incorrect. Further, with wages in Poland still up to five times lower than in the UK job-to-job mobility may not be people's first requirement.

2.4 With direct company recruitment the study found that it was evident that employers are beginning to use a number of resources to try to source Polish labour

${ }^{5}$ Carby-Hall, J. (2007) The Treatment of Polish and Other A8 Economic Migrants in the European Union Member States, report for the Commissioner for Civil Rights Protection of the Republic of Poland.

6 Vignon, J. (2007) Drawing the lessons from the European year for workers mobility, presentation to the 'Economic Migration in the European Union - Problems and Challenges' conference, Warsaw 24 ${ }^{\text {th }}$ September 2007. 
directly. For example, there are numerous web pages and Polish based newspapers advertising UK jobs. It was reported that companies are moving away from using Polish and beginning to use English for advertisements. In Poland it was reported that job fairs were a common means of staff recruit. This was sometimes based on a particular trade, for example bus drivers who were recruited on mass with UK union collaboration due to local shortages (Fitzgerald 2005). In North West construction and both food processing sectors this was not noted as an overall main recruitment strategy. Although, in North East construction it was the main route into employment for many of the Polish workers encountered. Here the most worrying signs regarding skilled trades were evident. Sub contractors had directly recruited skilled workers from Poland and introduced them onto building sites at wages below the national industry (the Working Rule Agreement) and minimum wage level (Fitzgerald 2006). The trade unions were often found to be 'policing' the skilled rate for the job, not only for the direct interests of members but also to contain the early signs of antagonism to the newly arrived groups of Polish workers. Ucatt also managed to assist some skilled Polish workers onto one main contractors core workforce with agreed rates of pay and conditions secured. This situation was also identified with regard to engineering construction skill rates (the National Agreement for the Engineering Construction Industry), which were again being undermined through the introduction by sub contractors of cheaper skilled workers from A8 countries (Fitzgerald, 2008). Here a union, in collaboration with the employer, has introduced a limited strategy of wage transparency to maintain the skilled rates.

2.5 The final direct agency recruitment route was identified as the most prevalent. Here agencies are either directly employing Poles and then moving them from workplace to workplace as required (dominant in food processing); or provided a supply service for UK companies, with recipient companies becoming the final employer of Poles. A representative of the British Polish Chamber of Commerce (BPCC) in Poland noted that agencies had now become their largest single member group in Poland. The President of the Federation of Poles in Great Britain also highlighted the significance of agencies for UK recruitment in general and this view was echoed by a number of Polish regional respondents. Agencies have committed some of the worst excesses of abuse of Polish workers and the BPCC representative stated that they were working with EURES in Poland to identify the worst perpetrators. In construction in the North West agencies provided the sole route identified for both skilled and unskilled labour. Whilst in food processing they again provided the main route in both regions for mainly low skilled Polish workers.

\section{Discussion}

3.1 The rapid entry of Polish workers into the UK following their accession in May 2004 caught everyone by surprise. Often these workers came either 'on spec' or 
through fraudulent agencies and were left destitute and/or exploited with the worst excesses of a free market not uncommon and in some cases still remaining. From the Polish point of view this situation has improved with support networks forming, most notably around the web, the church, and through local UK activist from the traditional Polish community (Fitzgerald 2008). Local NGOs (e.g. Citizens Advice Bureau), trade unions and some local councils have engaged with the new entrants and provided valuable assistance. What was absent here was any form of government co-ordination at a local, regional or national level. In my opinion the migration is now consolidating with children and families arriving and employers and businesses (banks and other private service providers) all coming to terms and adapting to change. When we talk of Polish workers and skills, in many cases this must be considered within the wider context of this overall story of recent EU accession migration.

3.2 Given the above it is clearly evident that a choice has to be made by UK Government and its agencies on how far to engage with this continued EU accession migration and its operation within a free European market. Often when we discuss skills, we discuss the short-term or crisis management of skill needs. For example, in construction large subcontractors are under heavy financial pressures to deliver contracts on time. They in turn need skills, often on a project by project basis and due to this a geographically mobile UK and European construction workforce has emerged. However, in the North the evidence suggests that in recent years a new phenomenon has been introduced into this of not only posted workers ${ }^{7}$ on Polish conditions of service but also the open recruitment of teams of skilled workers paid below industry and minimum wage levels. This may initially not create issues for Polish or other A8 workers, and the contracts that they work on may be delivered on time, but it most certainly creates issues on building sites and in local communities with indigenous workers who feel threatened. There are real concerns here that wages and conditions will reduce if this becomes increasingly the norm. Trade union officials in food processing and transport have reported that this has started to occur and even spoke of indigenous workers being replaced by cheaper A8 workers (see Fitzgerald 2007b). If skilled Polish workers are to continue working in the UK then co-ordination led by Government is needed, with properly policed regulations.

3.3 A choice also exists for Government with regard to those Polish workers currently working in occupations below their current capabilities, training and qualifications. One of the most significant contributions that the trade union

7 The Posted Workers Directive has caused much debate but has been used here to bring over A8 workers, all of whom have been paid below the industry skilled rates and some below even the minimum wage (see Fitzgerald 2008) 
movement has made in supporting people to reach their full potential, assisting the skill needs of the labour market, is through the provision of union learning representatives (ULRs). Funded by government, and often supported by employers, ULRs have encouraged and supported many to begin to develop not only their skills in the workplace but also to take the first steps into further and higher education. ULRs have often used this experience to support Polish workers when they have come into workplaces and communities. Here in particular Poles have learnt English, often through Esol classes. However, these classes, frequently free to migrant workers, are now being withdrawn, and are unlikely to be further supported as Esol provision often does not equate to enrolments on National Qualification Framework (NQF) courses $^{8}$. This situation should be addressed as language can be an issue holding back many Polish workers from making an increasing contribution to the UK economy. If there is Government supported co-ordination then many Poles currently working in unskilled UK jobs can progress and make a fuller contribution to UK skill needs and our overall economy. Government may believe that the real issue here is the cost effectiveness of supporting transitory Polish workers. But if we do not adopt a coordinated approach are we to 'brush this migration under the carpet' with another opportunity missed, it should be remembered that the mobility of European workers is likely to continue and surely there is no going back.

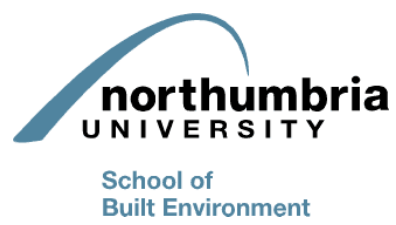

${ }^{8}$ LSC (2007) Migrant Workers and the Labour Market: Review of LSC research on labour market participation, skills and skills provision for migrant workers, Learning and Skills Council report, January 2007. 